\title{
Visual Communication Profession Practice Design in Studio Teaching Mode
}

\author{
Du Yan
}

School of Arts, Xi'an University, 710065

\section{Keywords: Studio Teaching Mode; Visual Communication; Practical Ability; Design Expression}

\begin{abstract}
With the continuous progress and development of society, humanity has fully entered the information age. As the expression language of traditional design art, visual communication design is no longer just sticking to the design art expressed in the traditional sense, but more to an abstract expression. This kind of expression comprehensively describes to us the cultural phenomena of society and the progress of social civilization. Nowadays, in order to improve the professional application ability of students, and at the same time cultivate students' research ability and the ability to undertake technical projects, a teaching mode combining teaching with production, theory and practice has gradually been formed. This kind of teaching mode integrating production, research, practice and teaching is the popular studio teaching mode. This kind of teaching mode takes a new style of cultivation mode to open up the way for the visual communication profession teaching in colleges and universities, and is highly praised by many colleges and universities. This article discusses the problems in the professional implementation of the studio teaching mode from the perspective of the cultivation of innovative talents and students' entrepreneurial ability. Based on the feasibility and necessity of this mode, a preliminary discussion was made on the design of visual communication profession practice.
\end{abstract}

\section{Concept of Visual Communication Profession}

Things that the human eye sees, such as text, architecture, plastic art, television and film, and photography are all called visual symbols. The visual communication of these visual symbols refers to a process in which a certain purpose is used as a guide for the conveyed object to convey certain specific information and influence it. The entire communication process is accomplished through a visual art form.

Visual communication design has been widely welcomed by people for its unique practicality and applicability. As an art aiming at serving the modern society, it has a profound influence on people's concepts and thinking with unique artistic charm, and it also acts on people's daily life. Therefore, teachers should aim at stimulating and cultivating students' innovative thinking in teaching visual communication design. Focusing on professional practice classes and basic application classes, an enlightening and developmental education mode is used to motivate students' enthusiasm and guide students in innovative design and practice. This practice has led teachers to abandon the traditional teaching mode of comprehensive technology and theory. When students acquire knowledge, they can also switch from traditional unilateral teaching from teachers to practical application and accumulation. Designers of all walks of life communicate their expressed information to the audience by visual symbols such as graphics, text, and color. Visual communication design now affects all aspects of people's lives and plays an important role.

\section{The Meaning, Necessity and Feasibility of Studio Teaching Mode}

The Basic Meaning of Studio Teaching Mode. The studio teaching mode is generally managed in a unified manner by various institutions. With a stable team of professors and experts as the core, the team will make full use of the various resources outside the school and on campus during the process of scientific research and teaching. In other words, this mode is a practical teaching mode that combines the characteristics of various professions with traditional teaching laws.

The Feasibility and Necessity of Studio Teaching Mode. The studio teaching mode was born 
in the period of the great industrial development in Germany, which was pioneered by Bauhaus in Weimar. This breaks the stereotyped teaching mode of traditional teaching that pays more attention to theory and ignores practice, and introduces the process that students practice in person, which effectively stimulates students' potential creative ability. Bauhaus believes that art is a natural talent, and that manual skills and craftsmanship belong to acquired cultivating ability. To create opportunities for students to realize their dream of designing and to create a new era in which industrial production and modern design are combined, Bauhaus' teaching method advocates extensive contacts between the industrial and business communities. Nowadays, academic circles have done a lot of research and exploration on the studio teaching mode and recognized it. This teaching mode is also often used in visual communication design teaching to provide teachers with an open practice environment in cultivating students' innovative ability, adaptability and practical ability. At the same time, a teaching mode that closely combines design practice and teaching opens up new avenues for the reform of visual communication teaching and improves the practical significance of teaching. This studio teaching mode plays an important role in solving students' employment problems, social adaptability, and improving professional abilities, and is highly respected by many design universities.

\section{Today's Visual Communication Profession Practice Teaching Project Innovation in Studio Teaching Mode}

The development of practical teaching based on visual communication design in the studio teaching mode depends on whether the student's cognitive thinking pattern is consistent with the profession. The profession also needs to meet market conditions, which is conducive to mutual communication and supervision between teachers and students. At present, from the perspective of students' cognitive laws and thinking characteristics, teaching practice projects are divided into three practices, integrated design practice, basic practice, and research and exploration practice.

The Cognitive Purpose of Basic Practice Is Proficiency and Mastery. This type of practice consists mainly of three kinds of practical content, that is, perception, cognition, and verification. Therefore, students' basic cognitive level can be improved and they can learn about related theories, skills, and methods.

The Cognitive Purpose of Integrated Design Practice Is Application and Synthesis. Students mainly study basic professional courses before actual practice and learning content is basically biased towards the phenomena that occur in real life. At this time, this type of learning mode is very suitable for students to find out the answers to the questions to be solved. It is worth noting that when designing this type of practice, it is necessary not only to ensure that students develop a divergent thinking mode when they are aware of the problem, but also to make students aware of the seriousness of the research project task in the early stages of practice. Students should also be proficient in the processing methods and techniques of various materials, which in turn enable them to strengthen their creative thinking and operation skills.

Deepening Research Cognition Is the Main Goal of Research and Exploration Practice. The subject is the core of the research and exploration practice mode. Whether it is students helping tutors or students actively designing projects to reflect on social issues when they graduate from design, the main result is the selection of topics. Only by selecting suitable topics can teachers and students master the core theories and methods. When dealing with problems, only in the spirit of delving into the problem, can we deal with it reasonably and effectively in the final laboratory training room, so that the overall level of practice can be improved.

From the perspective of studio teaching mode, this kind of visual communication professional practice project training needs to construct a complete and reasonable course system. In order to realize the integration of students' theory and practice, tradition and innovation, curriculum design is combined with the above three practical contents and social reality. 


\section{Main Problems Faced in the Current Studio Teaching Mode in the Design of Visual Communication Profession Practice}

The Project Subject Determines the Direction of the Studio Teaching Mode. The richness of the project determines the development process of the studio teaching. A typical small studio will limit the research directions and results of internal members. For example, a studio organized by a department can easily limit the academic composition of members. On the other hand, when the studio involves a wide range of topics in the project, teaching and research are likely to lack breadth and depth. Due to the close correlation between design and carrier, the level of final design results is relatively shallow. For example, in the field of packaging design, a wide range of packaging materials are distinguished from each other. It is difficult for a studio to have an in-depth understanding of each type of packaging material, which can easily lead to unmatched posts. This will inevitably lead to the development of low-level design results, resulting in some technical defects.

Art Design Is A Comprehensive Discipline As A Product of the Combination of Craft and Art. The discipline not only requires students to master and use various types of knowledge and skills comprehensively, but also has a higher requirement for teachers. Teachers must have access to various disciplines in their daily life and learning, have extensive contact with their relevant knowledge areas, and have a high level of overall quality. Although the prevailing studios today are more reasonable in teacher composition, teachers in different professional fields lack communication. This directly makes the progress of the studio project unsmooth, which in turn makes it difficult for students to comprehensively master and use various types of knowledge and skills. For example, art teachers and engineering teachers in packaging design studios can have complementary knowledge gaps with each other. If they do not communicate with each other, they will cause many different types of defects in packaging design work, which will result in a decline in teaching achievement.

\section{Corresponding Improvement Methods}

In the visual communication profession, these studio teaching mode problems are now widespread and need to be continuously improved. The author puts forward a few suggestions for this aspect in the following points, with a view to make the studio teaching mode better.

Set the Main Direction for the Specific Studio Project. The project selection is scientific and professional. This practice not only helps the teacher to be more targeted in counseling, but also helps to cultivate the students' special ability. In turn, the design level of the studio has been greatly improved, thus opening up a vast space for long-term cooperation with the company.

Promote Communication and Cooperation Among Teachers in the Studio. In the studio, teachers are encouraged to communicate with each other and learn from each other, understand their professional focus in the teaching process, and learn more about each other's knowledge. It can be conducted through regular teaching and research activities, mutual skills learning and academic exchanges. In this way, teachers' own professional abilities will be improved and students' learning process will be more consistent and optimized. Finally, the professional level of studio design and production will be significantly improved.

\section{How to Ensure the Implementation of Improvement Measures}

Improve the Quality of Teachers. The key to visual communication professional practice teaching depends on the teacher. It is crucial whether the teacher has a strong comprehensive practice level and whether they can effectively guide the students' practical ability. Therefore, in order to ensure the smooth implementation of the practical teaching of visual communication profession, schools should strengthen the training of teachers, establish a clear-looking studio and establish a faculty 
with high teaching standards and proficient in education. At the same time, teachers must also enrich their own practical experience in social practice and enhance their own design and practice abilities so as to prepare for the successful implementation of practical teaching.

Strengthen the Construction of Training Bases. In order to improve students' practical and application ability, and strengthen teachers' practical teaching, the construction of training bases inside and outside school is indispensable for visual communication professional practice. In carrying out this work, on the one hand, in order to ensure the close relationship between the development of the social industry and studio teaching, the combination of actual projects and practical teaching in the school requires the establishment of a more standardized and long-term studio. On the other hand, in order to ensure the effective cultivation of students' adaptability and practical ability, and actively guide students to meet the needs of society, it is necessary to strengthen the construction of off-campus training bases to carry out targeted practical activities.

Strengthen the Supervision and Control of the Quality of Practical Teaching and Promote the Overall Reform of Practical Teaching. The quality of regulatory control is mainly directed at students and teachers. It is mainly to understand and test students' practical abilities and to check teachers' teaching results. The key to visual communication professional practice teaching in the studio teaching mode lies in teachers and students. Through this feedback-based inspection method, it will not only improve teachers' teaching standards, but also enhance students' practical ability.

In a word, the visual communication profession practice teaching under the studio teaching mode helps students to solve the theoretical problems and cultivate students' divergent innovative thinking ability. It also cultivates their practical ability to analyze and solve problem through connecting with the current status of the society. Under such great competitive pressure, the visual communication profession practice teaching under the studio teaching mode is particularly important.

\section{Conclusion}

With the rapid development of China's national power, the visual communication profession has gradually been paid attention to by the people. The visual communication profession practice in the studio teaching mode has also achieved good results and is gradually being widely referenced by the education community. As a bridge between enterprise production and school education, studio teaching mode is gradually perfecting its own attributes and functions. In order to ensure the steady improvement of teaching quality, the successful completion of teaching tasks, and to reasonably follow the guiding principles of curriculum construction, the campus needs to strengthen the relevance between the curriculum system and the practice of teaching content in the subsequent education reform. It is necessary to build a curriculum system that can train high-quality, applied, and comprehensive talents, and do a good job in the reform and construction of specialized courses.

\section{Reference}

[1] Y. H. Feng. Discussion on the Studio System Teaching of Art and Technology [J]. Art Observation, 2009 (10).

[2] H. Y. Zhao. Research on the Establishment of Studio System for Visual Communication Design Profession [D]. Beijing: Capital Normal University Press, 2016.

[3] Y. D. Sun. Enthusiasticity, Innovation and Entrepreneurship: An Art Design Talent Cultivation Mode Based on Studio System [J]. Decoration, 2009(2).

[4] Y. Xiao. Integration - Teaching and Learning in the Studio [C]. 2005 National Visual Communication Design Education Forum Proceedings, 2015.

[5] G. Li. Modern Design Studio System Research [J]. Advanced Architectural Education, 2008.

[6] L. Liu, L. Y. Chen and L. Wang. Exploration of the "Creative Studio" Teaching Mode for Graphic Image Production Profession [J]. Talents, 2010(32).

[7] C. M. Zhang. Research on the Application of Studio Teaching Mode in Industrial Design of Universities [D]. Shenyang Normal University, 2012.

[8] L. Tong. Research on Teaching Mode of Tutor Studio System for Visual Communication Artistic 
Design Profession [J]. Brand, 2014(11): 233-234.

[9]J. Yang. The Rational Thinking of Visual Communication Design Profession Studio Teaching [J]. Studies of Fine Arts Education, 2014(11):141-142.

[10]Z. He. Visual Communication Art Design in the New Media Era: Study on the Influence of New Media Art on Visual Communication Design Art [J]. Fine Arts. 2009 (07). 